\title{
Preparation and Evaluation of Emulsomes as a Drug Delivery System for Bifonazole
}

\author{
Vedanshu Malviya \\ Department of Pharmaceutics, PR Pote Patil College of Pharmacy, Amravati, Maharashtra, INDIA.
}

\begin{abstract}
Purpose: The main objective of present study is to evaluate the effect of various factors which have direct influence on the characteristic parameters of emulsomes formulation, so that optimized combination of factors can be find out which meet the high level of set desirability criteria. The present work is focused on the optimization of emulsomes formulation by applying Box-Behnken design (BBD) of experiment. Emulsomes are the modified form of emulsomes which consists of solid lipid core surrounded by phospholipid bilayer. Methods: Emulsomes were prepared by lipid film hydration method using Phosphatidylcholine (PHL), Tristearin (TRI), Stearylamine (STR), Cholesterol (CHOL) and Bifonazole as drug candidate. Formulations were optimized by using three factor three levels Box-Behnken (BBD) design of experiment. BBD was applied considering 3 factors as independent variables viz. Phospholipid ratio to Drug (A), Phospholipid to Tristearin ratio $(B)$ and Phospholipid ratio to Stearylamine $(C)$ at 3 levels $(-1,0,+1)$ to study their effect on dependent variables viz. Particle size (Y1), Zeta Potential (Y2) and Entrapment efficiency (Y3). Results of independent variables ( $A, B, C)$ were analysed to construct quadratic equation and $3-D$ response surface curves for each dependent variable (Y1, Y2, Y3). Results: The optimized formulation was selected on the basis of desirability criteria of minimum particle size, maximum zeta potential and maximum entrapment efficiency. The final optimized formulation has predicted particle size $(390.394 \mathrm{~nm})$, zeta potential $(45.0 \mathrm{mV})$ and entrapment efficiency $(81.642 \%)$. Conclusion: BBD is remarkable design of experiment for studying the effect of 3-factors at 3-levels on the responses in optimizing the emulsomes formulation.
\end{abstract}

Key words: Box-Behnken Design (BBD), Emulsomes, Bifonazole, Phospholipid, Stearylamine, Tristearin.

\section{INTRODUCTION}

In past few decade vesicular drug delivery system become area of interest for most of researchers. Emulsomes are among most common vesicular drug delivery carrier which is composed of phospholipid bilayer with aqueous core. Due to aqueous core it becomes limitation of emulsomes is to encapsulate lipophilic drugs. ${ }^{1,2}$ To overcome this problem new vesicular drugs delivery system was developed which is modified form of emulsomes known as Emulsomes. ${ }^{3}$ Emulsomes are new generation colloidal carrier system encompassing of solid lipid core composed of triglycerides stabilized by phospholipid bilayer envelop of one or more layers. ${ }^{4,5}$ Emulsomes have characteristics of both emulsomes and emulsion thus provide advantage over emulsomes of having more drug loading of lipophilic drugs, as the drug is encapsulated both in phospholipid bilayer as well as lipidcore. ${ }^{6}$ Emulsomes also provides sustained release of entrapped drug as compared to Liposome and the sustained release may be achieved upto $24 \mathrm{hr}^{7}$ There are many factors affecting formulation of emulsomes such as lipid material used along with properties of drug to be incorporated. Some studies have demonstrated that ingredients like choice of phospholipids, triglycerides, charge inducers, drug candidate and their concentrations significantly affected the
Submission Date: 14-07-2020; Revision Date: 04-12-2020; Accepted Date: 09-02-2021

DOI: 10.5530/ijper.55.1.12 Correspondence: Prof. Vedanshu Malviya Department of

Pharmaceutics, PR Pote Patil College of Pharmacy, Amravati-444604, Maharashtra, INDIA. Phone no: +91 8329652503 Email id: vedanshumlv56@ gmail.com

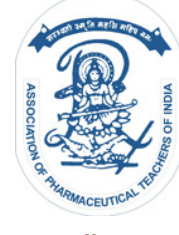

www.ijper.org 
physicochemical properties of emulsomes. Various characteristic properties of emulsomes such as particle size, drug release and entrapment efficiency is controlled by varying the relative amount of lipid and other ingredients in the formulation. In formulation development process study is required to understand detailed relationship between process parameters and quality attributes. In recent years many statistical methods were applied to investigate the effect of process variables on the quality attributes of formulation. Almost more than $50 \%$ of vesicular drug delivery systems having sustained release effect are optimized by using different designs of experiment. ${ }^{8}$ Traditionally various designs were used for optimization of process variables considering single factor at a time while keeping other factors constant and focused on only one factor at a time, which does not show the interaction effect of factors. ${ }^{9,10}$ In recent years more elaborated designs were developed using multiple factor study at a time. ${ }^{11}$

Response surface methodology is effective tool for optimizing process variables, which includes Doehlert Matrix (DM), Central Composite Design (CCD) and Box-Behnken design (BBD). Box-behnken design of experiment is mostly used for studying 3-factors at 3-levels. In this design response of independent variables are explored and data is modelled to generate mathematical relationship between independent variable and dependent variables in form of quadratic equation. This equation helps to study the effect of independent variables on the dependent variables. Response is also studied by 2-dimensional (2-D) 3-dimensional (3-D) graphical representation known as response surfaces. In these graphs response is plotted between two independent variables and one dependent variable. The geometrical illustration of a response by plotting two independent variables at a time keeping other variables constant is known as contour plots. ${ }^{12}$

Bifonazole 1-[phenyl-(4-phenylphenyl)methyl]imidazole is an imidazole antifungal drug indicated against skin or mucosal mycoses. Its topical use requires in depth drug retention in skin because the pathogenicity of dermatomycoses is related to their ability to gain access to other target tissues. Bifonazole is having a half-life of approx. $7 \mathrm{hr}$ with low bioavailability and also has a very low aqueous solubility. ${ }^{13,14}$

\section{MATERIALS AND METHODS}

Bifonazole was obtained as a gift sample from Vital Labs, Gujarat. Lecithin and Tristearin were procured from HiMedia. Cholesterol was procured from LOBA Chemie, Mumbai; Stearylamine (Octadecylamine) was procured from Ottokemi, Mumbai. Sephadex G-50 was procured form Yarrowchem Pvt Ltd, Mumbai. All other chemicals, solvents and reagents used were of analytical grade.

\section{Standard Calibration Curve}

The standard calibration curve of bifonazole was carried out on UV spectrophotometer by using phosphate buffer as the solvent. From solution having concentration $100 \mu \mathrm{g} / \mathrm{ml}$ samples of $0.5,1,1.5,2,2.5,3,3.5,4,4.5$ and $5 \mathrm{ml}$ were pipette out into $10 \mathrm{ml}$ volumetric flasks. The volume was made up to the mark with Phosphate buffer 6.8 to get the final concentration of $5,10,15,20,25,30$, $35,40,45$ and $50 \mu \mathrm{g} / \mathrm{ml}$ respectively. The absorbance of concentration was measured at $254 \mathrm{~nm} .{ }^{15}$

\section{Preparation of Emulsomes}

In preliminary studies trial batches were prepared to check the feasibility of method of preparation. Three factors i.e. Phospholipid to Bifonazole ratio, Phospholipid to Tristearin ratio; Phospholipid to Stearylamine ratio were studied considering Lecithin to Cholesterol ratio (1:0.5), sonication time $(12 \mathrm{~min})^{16,17}$ fixed to study their effect on Particle size, Zeta potential and Entrapment efficiency.

Bifonazole loaded emulsomes were prepared by lipid film hydration method. ${ }^{18,19}$ Accurately weighed amount of lecithin, cholesterol, tristearin, stearylamine were transferred into $500 \mathrm{ml}$ round bottom flask and mixture was dissolved in $10 \mathrm{ml}$ of chloroform. In another vessel accurately weighed bifonazole was dissolved in small quantity of methanol. After complete dissolution of ingredients both the solutions were mixed in round bottom flask. Volatile liquid has been evaporated using rotatory flash evaporator to obtain thin dry film on the inner wall of round bottom flask. Dry film was then hydrated overnight using phosphate buffer saline (PBS) of $\mathrm{pH}$ 7.4. After hydration milky coloured dispersion was obtained which was subjected to sonication for 12 min to obtain vesicles of desired size range. Dispersion was filtered through Sephadex G-50 column to remove unformed vesicles and unentrapped drug.

\section{Experimental Design}

To optimize the formulations Box-behnken design of experiment was used, which is a response surface type design of experiment, wherein responses of three factors were studied at three levels. ${ }^{18-22}$ Three factors considered were Phospholipid to Bifonazole ratio (A); Phospholipid to Tristearin ratio (B) and Phospholipid to Stearylamine ratio $(C)$ at three levels upper, middle and lower level $(+1,0,-1)$ as shown in (Table 1). All the experiments were performed in triplicate and average of 
each value is considered for further evaluation. A total no. of 17 experiments were designed with 5 centre points and 12 points at edges of design space for estimation of pure error sum of squares to choose best model among linear, two factor interaction and quadriatic model due to analysis of variance (ANOVA), $F$ - value. ${ }^{23}$ The effect of above mentioned independent variables $(A, B, C)$ were studied on dependent variables i.e. Particle size (Y1), Zeta potential (Y2) and Entrapment efficiency (Y3) by constructing their response surface two- dimensional and three-dimensional (2-D and 3-D) models along with quadratic equation using design expert software. The designed quadratic polynomial equation generated is as follows:

$$
\begin{aligned}
\mathrm{Y} 0= & \mathrm{b} 0 \mathrm{X} 1+\mathrm{b} 2 \mathrm{X} 2+\mathrm{b} 2 \mathrm{X} 2+\mathrm{b} 3 \mathrm{X} 4+\mathrm{b} 12 \mathrm{X} 2+ \\
& \mathrm{b} 13 \mathrm{X} 1 \mathrm{X} 3+\mathrm{b} 23 \mathrm{X} 2 \mathrm{X} 3+\mathrm{b} 11 \mathrm{X} 1^{2}+ \\
& \mathrm{b} 22 \mathrm{X} 2^{2}+\mathrm{b} 33 \mathrm{X} 3^{2}
\end{aligned}
$$

Where $\mathrm{Y} 0$ is response for each dependent variable; is an intercept; b1, b2, b3, b12, b13, b23, b11, b22, b33 are regressed coefficients from experimental response values of $\mathrm{Y}$; X1, X2, X3 and their combinations (X1X2, X1X3, $\mathrm{X} 2 \mathrm{X} 3)$ and square values $\left(\mathrm{X} 1^{2}, \mathrm{X} 2^{2}, \mathrm{X} 3^{2}\right)$ represented terms for studying interactive effect of two factors on response at same time simultaneously and to evaluate the fitness of the model, predicted R2 and adjusted R2. The coded values and actual values used in experimental runs of independent variables $(\mathrm{A}, \mathrm{B}, \mathrm{C})$ and their response on dependent variables (Y1, Y2, Y3) are shown in (Table 2).

\section{Evaluation Parameters}

Characterization Determination of Particle size and Zeta potential: All the samples from prepared batches were analysed in triplicate in aqueous medium. Average particle size and zeta potential were measured

\begin{tabular}{|c|c|c|c|c|c|c|c|c|c|}
\hline \multirow{4}{*}{$\begin{array}{l}\text { Experimental } \\
\text { Runs }\end{array}$} & \multirow{2}{*}{\multicolumn{2}{|c|}{$\frac{\text { Factor A }}{\text { (DR:PHL) }}$}} & \multirow{2}{*}{\multicolumn{2}{|c|}{$\begin{array}{l}\text { Factor B } \\
\text { (TRI:PHL) }\end{array}$}} & \multirow{2}{*}{\multicolumn{2}{|c|}{$\begin{array}{c}\text { Factor C } \\
\text { (STR:PHL) }\end{array}$}} & \multirow{2}{*}{$\begin{array}{c}\text { Response } \\
\text { (Y1) }\end{array}$} & \multirow{2}{*}{$\begin{array}{l}\text { Response } \\
\text { (Y2) }\end{array}$} & \multirow{2}{*}{$\begin{array}{c}\text { Response } \\
\text { (Y3) }\end{array}$} \\
\hline & & & & & & & & & \\
\hline & \multicolumn{2}{|c|}{$\begin{array}{l}\% \text { w/w of total } \\
\text { Phospholipid }\end{array}$} & \multicolumn{2}{|c|}{$\begin{array}{l}\% \text { w/w of total } \\
\text { Phospholipid }\end{array}$} & \multicolumn{2}{|c|}{$\begin{array}{l}\% \text { w/w of total } \\
\text { Phospholipid }\end{array}$} & Size & $\begin{array}{c}\text { Zeta } \\
\text { Potential }\end{array}$ & $\begin{array}{c}\text { Entrapment } \\
\text { Efficiency }\end{array}$ \\
\hline & Coded & $\begin{array}{l}\text { Actual } \\
\text { (in } \mathrm{mg} \text { ) }\end{array}$ & Coded & $\begin{array}{l}\text { Actual } \\
\text { (in } \mathrm{mg} \text { ) }\end{array}$ & Coded & $\begin{array}{l}\text { Actual } \\
\text { (in } \mathrm{mg} \text { ) }\end{array}$ & $\mathrm{nm}$ & $\mathrm{mV}$ & $\%$ age \\
\hline 1 & -1 & 1 & -1 & 50 & 0 & 10 & 206 & 56.4 & 69.42 \\
\hline 2 & 1 & 5 & -1 & 50 & 0 & 10 & 405 & 57.4 & 76.46 \\
\hline 3 & -1 & 1 & 1 & 150 & 0 & 10 & 564 & 52.1 & 78.67 \\
\hline 4 & 1 & 5 & 1 & 150 & 0 & 10 & 641 & 55.8 & 88.46 \\
\hline 5 & -1 & 1 & 0 & 100 & -1 & 5 & 432 & 27.8 & 74.82 \\
\hline 6 & 1 & 5 & 0 & 100 & -1 & 5 & 488 & 28.3 & 81.67 \\
\hline 7 & -1 & 1 & 0 & 100 & 1 & 15 & 651 & 66.8 & 73.41 \\
\hline 8 & 1 & 5 & 0 & 100 & 1 & 15 & 780 & 59.3 & 83.88 \\
\hline 9 & 0 & 3 & -1 & 50 & -1 & 5 & 189 & 22.6 & 69.68 \\
\hline 10 & 0 & 3 & 1 & 150 & -1 & 5 & 492 & 25.7 & 75.46 \\
\hline 11 & 0 & 3 & -1 & 50 & 1 & 15 & 489 & 68.5 & 72.78 \\
\hline 12 & 0 & 3 & 1 & 150 & 1 & 15 & 678 & 64.4 & 77.67 \\
\hline 13 & 0 & 3 & 0 & 100 & 0 & 10 & 378 & 42.3 & 80.56 \\
\hline 14 & 0 & 3 & 0 & 100 & 0 & 10 & 392 & 45.5 & 82.02 \\
\hline 15 & 0 & 3 & 0 & 100 & 0 & 10 & 365 & 44.1 & 79.96 \\
\hline 16 & 0 & 3 & 0 & 100 & 0 & 10 & 388 & 48.7 & 81.78 \\
\hline 17 & 0 & 3 & 0 & 100 & 0 & 10 & 390 & 44.8 & 79.41 \\
\hline
\end{tabular}
by photon correlation spectroscopy (PCS; Zetasizer,

\begin{tabular}{|c|c|c|c|c|}
\hline \multirow{2}{*}{ Table 1: Variables and their levels in Box-Behnken design. } \\
\cline { 3 - 5 } Variable Code & \multirow{2}{*}{ Variable } & \multicolumn{3}{|c|}{ Coded values/actual values } \\
\hline A & Phospholipid to Drug (\%w/w) & $5 \%(5 \mathrm{mg})$ & $\mathbf{0}$ & $\mathbf{- 1}$ \\
\hline B & Phospholipid to Tristearin ratio (TRI:PHL) $(\% \mathrm{mg} / \mathrm{w})$ & $1 \%(1 \mathrm{mg})$ \\
\hline C & Phospholipid to Stearylamine ratio (STR:PHL) $(\% \mathrm{w} / \mathrm{w})$ & $150 \%(150 \mathrm{mg})$ & $100 \%(100 \mathrm{mg})$ & $50 \%(50 \mathrm{mg})$ \\
\hline
\end{tabular}


HAS 3000; Malvern Instruments, Malvern, UK). All the measurements were carried out with an angle of $90^{\circ}$ at $25^{\circ} \mathrm{C} .{ }^{23}$

\section{Determination of Entrapment Efficiency}

Preparation of Sephadex G-50 Column: Sephadex G-50 was swelled in $10 \mathrm{ml}$ of $0.9 \%$ sodium chloride solution for $5 \mathrm{hr}$ at room temperature with occasional shaking. The gel so formed was stored at $4^{\circ} \mathrm{C} .2 \mathrm{ml}$ disposable syringe was taken and lower portion of syringe was plugged with filter paper and cotton. Sephadex gel was poured into syringe and gel filled syringe was further used as filter medium. Determination of drugs entrapment efficiency: Emulsomes dispersion was drop wise filtered through sephadex G-50 column. Filterate was treated with few drops of Triton X-100. Triton X100 breaks the phospholipid bilayer of emulsomes vesicles and entrapped drug comes out in solution, which was analysed by HPLC technique to determine the area under curve for evaluation of entrapped drug. ${ }^{24}$ Entrapment efficiency (EE) was calculated by following formula:

Entrapmen Efficiency $=\frac{\text { Amount of drug entrapped }}{\text { Total amount of drug used }} \times 100$

\section{RESULTS AND DISCUSSIONS}

Standard Calibration Curve: The standard calibration curve of bifonazole showed the linearity which follows the beers lamberts law by giving the equation of $\mathrm{y}=$ $0.0577 x+0.0711$ and $R^{2}$ value of 0.9981 which shows good linearity.

The observed results of independent variables of all 17 formulations were analysed using design expert software. Results showed that the different combinations of variables have significant effect on the responses of dependent variables viz. particle size $(\mathrm{Y} 1)$, zeta potential (Y2) and entrapment efficiency (Y3), which were shown in (Table 2) and actual and predicted values of response along with their \% error (residual) are shown in (Table 3). Actual experimental values are found in reasonable agreement with predicted values having insignificant difference in residual values.

As shown in (Table 4) Y1, Y2, Y3 were fitted with a quadratic model and result shows significant lack of fit $(P>0.05)$ for all the variables. Polynomial equation of each dependent variable were generated which explained the individual and interaction effect of independent variables on dependent variables. The positive signs in the polynomial equation show synergistic effect whereas negative signs represent the antagonistic effect on dependent variables.

Table 3: Point prediction check point for optimization actual value, experimental value and residual (\% error).

\begin{tabular}{|c|c|c|c|c|c|c|c|c|c|}
\hline \multirow{2}{*}{$\begin{array}{l}\text { Run } \\
\text { order }\end{array}$} & \multicolumn{3}{|c|}{ Particle Size (Y1) } & \multicolumn{3}{|c|}{ Zeta Potential (Y2) } & \multicolumn{3}{|c|}{ Entrapment Efficiency (Y3) } \\
\hline & $\begin{array}{l}\text { Actual } \\
\text { Value }\end{array}$ & $\begin{array}{l}\text { Predicted } \\
\text { Value }\end{array}$ & $\begin{array}{l}\text { Residual } \\
\text { (\%error) }\end{array}$ & $\begin{array}{l}\text { Actual } \\
\text { Value }\end{array}$ & $\begin{array}{l}\text { Predicted } \\
\text { Value }\end{array}$ & $\begin{array}{l}\text { Residual } \\
\text { (\%error) }\end{array}$ & $\begin{array}{l}\text { Actual } \\
\text { Value }\end{array}$ & $\begin{array}{l}\text { Predicted } \\
\text { Value }\end{array}$ & $\begin{array}{l}\text { Residual } \\
\text { (\%error) }\end{array}$ \\
\hline 1 & 206.00 & 230.13 & -24.13 & 56.40 & 57.25 & -0.8500 & 69.42 & 70.68 & -1.26 \\
\hline 2 & 405.00 & 406.38 & -1.38 & 57.40 & 55.32 & 2.08 & 76.46 & 77.84 & -1.38 \\
\hline 3 & 564.00 & 562.63 & 1.37 & 52.10 & 54.17 & -2.07 & 78.67 & 77.29 & 1.38 \\
\hline 4 & 641.00 & 616.88 & 24.12 & 55.80 & 54.95 & 0.8500 & 88.46 & 87.20 & 1.26 \\
\hline 5 & 432.00 & 423.75 & 8.25 & 27.80 & 24.51 & 3.29 & 74.82 & 74.32 & 0.5025 \\
\hline 6 & 488.00 & 502.50 & -14.50 & 28.30 & 27.94 & 0.3625 & 81.67 & 81.04 & 0.6250 \\
\hline 7 & 651.00 & 636.50 & 14.50 & 66.80 & 67.16 & -0.3625 & 73.41 & 74.03 & -0.6250 \\
\hline 8 & 780.00 & 788.25 & -8.25 & 59.30 & 62.59 & -3.29 & 83.88 & 84.38 & -0.5025 \\
\hline 9 & 189.00 & 173.13 & 15.88 & 22.60 & 25.04 & -2.44 & 69.68 & 68.92 & 0.7588 \\
\hline 10 & 492.00 & 501.63 & -9.63 & 25.70 & 26.91 & -1.21 & 75.46 & 77.35 & -1.89 \\
\hline 11 & 489.00 & 479.38 & 9.62 & 68.50 & 67.29 & 1.21 & 72.78 & 70.89 & 1.89 \\
\hline 12 & 678.00 & 693.88 & -15.88 & 64.40 & 61.96 & 2.44 & 77.67 & 78.43 & -0.7587 \\
\hline 13 & 378.00 & 382.60 & -4.60 & 42.30 & 45.08 & -2.78 & 80.56 & 80.75 & -0.1860 \\
\hline 14 & 392.00 & 382.60 & 9.40 & 45.50 & 45.08 & 0.4200 & 82.02 & 80.75 & 1.27 \\
\hline 15 & 365.00 & 382.60 & -17.60 & 44.10 & 45.08 & -0.9800 & 79.96 & 80.75 & -0.7860 \\
\hline 16 & 388.00 & 382.60 & 5.40 & 48.70 & 45.08 & 3.62 & 81.78 & 80.75 & 1.03 \\
\hline 17 & 390.00 & 382.60 & 7.40 & 44.80 & 45.08 & -0.2800 & 79.41 & 80.75 & -1.34 \\
\hline
\end{tabular}




\section{Particle Size (Y1)}

As shown in (Table 5 and 6 ) model $\mathrm{F}$ value for particle size was found $106.99(P<0.0001)$ which indicates that the model is significant. The lack of fit F-value of 6.40 $(P>0.05)$ which is not significant. This indicates good model fit. Correlation coefficient $\left(R^{2}=0.9928\right)$ for polynomial equation revealed significant data fitting in model. The predicted $R^{2}$ of 0.9025 is in reasonable agreement with the adjusted $R^{2}$ of 0.9835 indicates the adequacy of the model to predict the response of particle size. Adequate precision measures the signal to noise ratio. A ratio greater than 4 is desirable. Adequate precision in case of particle size is 39.289 , indicating an adequate signal and can be used to navigate the design space.

The second order polynomial equation relating the response of particle size (Y1) is given below:

$$
\begin{aligned}
\mathrm{Y} 1= & 382.60+57.63 A+135.75 B+124.63 C- \\
& 30.50 A B+18.25 A C-28.50 B C+98.58 A 2- \\
& 27.18 B 2+106.58 C 2
\end{aligned}
$$

As shown in quadratic equation individual factor $\mathrm{A}, \mathrm{B}$ and $\mathrm{C}$ have synergistic effect including combined effect of factor $\mathrm{A} \& \mathrm{C}$, whereas combined effect of factor $\mathrm{A}, \mathrm{B}$ and $B, C$ showed antagonistic effect on particle size. As per quadratic equation if the values of individual factor increased the particle size would increase. The increase in particle size with increasing the values of factor $\mathrm{A}, \mathrm{B}$ and $\mathrm{C}$ i.e. increasing \%age of Bifonazole, Tristearin and Stearylamine may be due to the facts that Tristearin is core material for Emulsomes and increase in \%age of Tristearin results in bulkier core as more amount of core is accumulated in Emulsomes vesicles. Stearylamine is charge inducer and increase in \%age of Stearylamine would induce more charge on the vesicles which results in more repulsion between phospholipid bilayer which in turns leads to increase particle size. 3-D response surface plots of particle size are shown in (Figure 1).

\section{Zeta Potential (Y2)}

As shown in (Table 5 and 6 ) model $\mathrm{F}$ value for size was found $37.75(p<0.0001)$ which indicates that the model is significant. The lack of fit F-value of $2.83(p>0.05)$

\begin{tabular}{|c|c|c|c|c|c|}
\hline Model & $\begin{array}{c}\text { Sequential } \\
p \text {-value }\end{array}$ & $\begin{array}{c}\text { Lack of fit } \\
p \text {-value }\end{array}$ & Adjusted $R^{2}$ & $\begin{array}{c}\text { Predicted } \\
R^{2}\end{array}$ & Remarks \\
\hline \multicolumn{6}{|c|}{ Response (Particle Size, Y1) } \\
\hline Linear & 0.0004 & 0.0003 & 0.6774 & 0.5363 & \\
\hline $2 \mathrm{FI}$ & 0.8362 & 0.0002 & 0.6135 & 0.1119 & \\
\hline Quadratic & $<0.0001$ & 0.0525 & 0.9835 & 0.9025 & Suggested \\
\hline \multicolumn{6}{|c|}{ Response (Zeta Potential, Y2) } \\
\hline Linear & $<0.0001$ & 0.0309 & 0.8505 & 0.7614 & \\
\hline $2 \mathrm{FI}$ & 0.8473 & 0.0184 & 0.8200 & 0.4877 & \\
\hline Quadratic & 0.0053 & 0.1705 & 0.9539 & 0.7704 & Suggested \\
\hline \multicolumn{6}{|c|}{ Response (Entrapment Efficiency, Y3) } \\
\hline Linear & 0.021 & 0.0195 & 0.5888 & 0.4077 & \\
\hline $2 \mathrm{FI}$ & 0.9195 & 0.0108 & 0.4902 & -0.1920 & \\
\hline Quadratic & 0.0005 & 0.3537 & 0.9340 & 0.7389 & Suggested \\
\hline
\end{tabular}

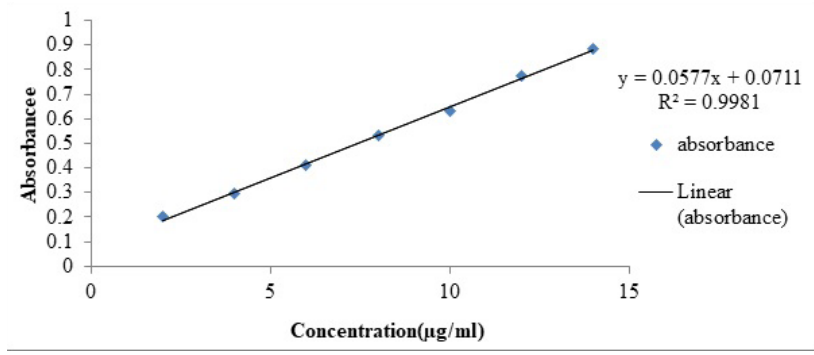

Figure 1: Standard Calibration Curve of Bifonazole.

\begin{tabular}{|c|c|c|c|c|c|c|c|}
\hline \multicolumn{7}{|c|}{ Table 5: Fit Statistic for responses Y1, Y2, Y3. } \\
\hline Response & $\boldsymbol{R}^{\mathbf{2}}$ & $\begin{array}{c}\text { Adjusted } \\
\boldsymbol{R}^{\mathbf{2}}\end{array}$ & $\begin{array}{c}\text { Predicted } \\
\boldsymbol{R}^{\mathbf{2}}\end{array}$ & $\begin{array}{c}\text { Adeq } \\
\text { Precision }\end{array}$ & Std. Dev. & Mean & \% CV \\
\hline Particle Size (Y1) & 0.9928 & 0.9835 & 0.9025 & 39.2891 & 20.41 & 466.35 & 4.38 \\
\hline Zeta Potential (Y2) & 0.9798 & 0.9539 & 0.7704 & 17.7890 & 3.14 & 47.68 & 6.58 \\
\hline Entrapment Efficiency (Y3) & 0.9711 & 0.9340 & 0.7389 & 16.7196 & 1.23 & 78.07 & 1.58 \\
\hline
\end{tabular}




\begin{tabular}{|c|c|c|c|}
\hline Result of the ANOVA & Particle Size (nm) & Zeta Potential (mV) & Entrapment Efficiency (\%) \\
\hline \multicolumn{4}{|l|}{ Regression } \\
\hline Sum of Squares & $4.013 E+05$ & 3339.59 & 358.02 \\
\hline Degree of freedom (df) & 9 & 9 & 9 \\
\hline Mean square & 44583.44 & 371.07 & 39.78 \\
\hline F-value & 106.99 & 37.75 & 26.16 \\
\hline$p$-value & $<0.0001$ & $<0.0001$ & $<0.0001$ \\
\hline Inference & Significant & Significant & Significant \\
\hline \multicolumn{4}{|l|}{ Lack of fit tests } \\
\hline Sum of squares & 2413.75 & 46.76 & 5.51 \\
\hline Degree of freedom (df) & 3 & 3 & 3 \\
\hline Mean square & 804.58 & 15.59 & 1.84 \\
\hline F-value & 6.40 & 2.83 & 1.43 \\
\hline$p$-value & 0.0525 & 0.1705 & 0.3575 \\
\hline Inference & Not significant & Not significant & Not significant \\
\hline \multicolumn{4}{|l|}{ Residual } \\
\hline Sum of Squares & 2916.95 & 68.81 & 10.64 \\
\hline Degree of freedom (df) & 7 & 7 & 7 \\
\hline Mean square & 416.71 & 9.83 & 1.52 \\
\hline
\end{tabular}

which is not significant. This indicates good model fit. Correlation coefficient $\left(R^{2}=0.9798\right)$ for polynomial equation revealed significant data fitting in model. The predicted $R^{2}$ of 0.7704 is in reasonable agreement with the adjusted $R^{2}$ of 0.9539 indicates the adequacy of the model to predict the response of zeta potential. Adequate precision measures the signal to noise ratio. A ratio greater than 4 is desirable. Adeq precision in case of zeta potential is 17.789 , indicating an adequate signal and can be used to navigate the design space. as shown in Figure 2. The second order polynomial equation relating the response of Zeta potential (Y2) is given below:

$$
\begin{aligned}
\mathrm{Y} 2= & 45.08-0.2875 A-0.8625 B+19.33 C+ \\
& 0.6750 A B-2.00 A C-1.80 B C+5.30 A 2+ \\
& 5.05 B 2-4.83 C 2
\end{aligned}
$$

As shown in quadratic equation individual factor $C$ and combined factors $\mathrm{AB}$ have synergistic effect, whereas individual factors $\mathrm{A}, \mathrm{B}$ and its combined factors $\mathrm{A}, \mathrm{C}$ and $\mathrm{B}, \mathrm{C}$ showed antagonistic effect on Zeta potential. The increases in value of Zeta potential with increasing the values of factor $\mathrm{C}$ i.e. increasing \%age of Stearylamine may be due to fact that Stearylamine is charge inducer and have direct influence on the charge of vesicles. 3-D response surface plots of zeta potential (Y2) are shown in (Figure 3).

\section{Entrapment Efficiency (Y3)}

As shown in "Table 5 and 6 " model F value for size was found $26.16(p<0.0001)$ which indicates that the model

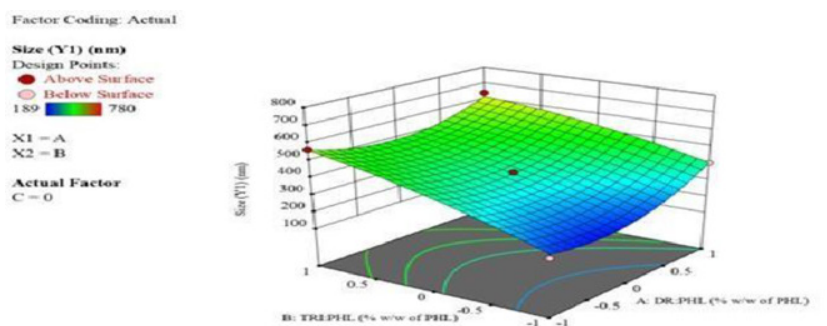

a.

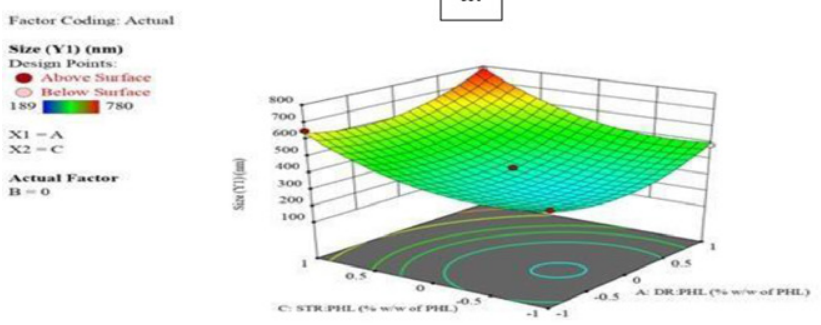

b.

Factor Coding: Actual Size (Y1) (nm)

Design Points:

- Above Surface
189 Below Surface
1880

$\mathrm{X} 1-\mathrm{B}$
$\mathrm{X} 2-\mathrm{C}$

Actual Factor 

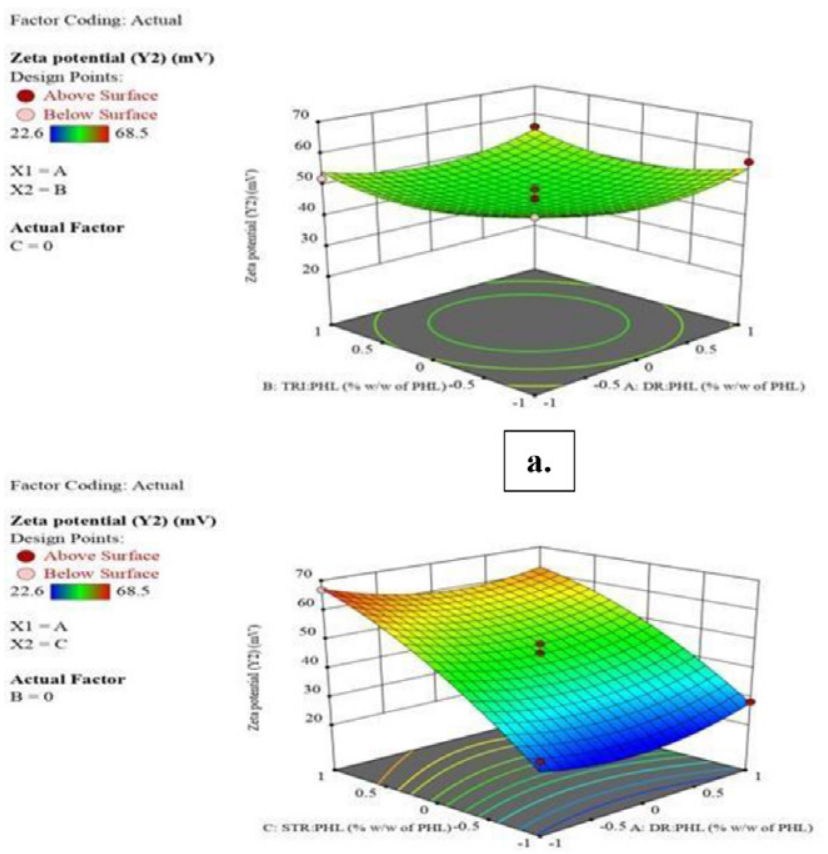

Factor Coding: Actual Zeta potential $(\mathrm{Y} 2)(\mathrm{mV})$ Design Points: - Above Surface 22.6 Below Surface $\mathrm{X} 1-\mathrm{B}$ $\mathrm{X} 1=\mathrm{B}$
$\mathrm{X} 2=\mathrm{C}$ Actual Factor $A=0$

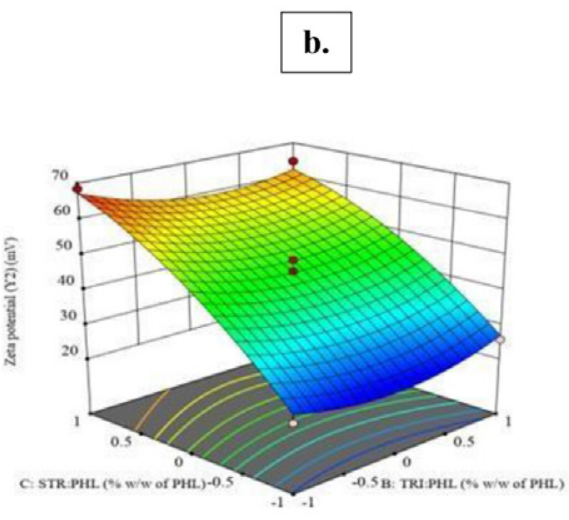

c.

Figure 3: 3-Dimensional response surface plots showing interaction effect of variable $A$ and $B(2 a), A$ and $C(2 b), B$ and C (2c) on zeta potential (Y2).

is significant. The lack of fit F-value of $1.43(p>0.05)$ which is not significant. Which indicates good model fit correlation coefficient $\left(R^{2}=0.9711\right)$ for polynomial equation revealed significant data fitting in model. The predicted $R^{2}$ of 0.7389 is in reasonable agreement with the adjusted $R^{2}$ of 0.9340 indicates the adequacy of the model to predict the response of entrapment efficiency. Adeq precision measures the signal to noise ratio. A ratio greater than 4 is desirable. Adeq precision in case of entrapment efficiency is 16.7196 , indicating an adequate signal and can be used to navigate the design space.

The second order polynomial equation relating the response of Entrapment efficiency (Y3) is given below:

$$
\begin{aligned}
\mathrm{Y} 3= & 80.75+4.40 A+3.27 B+0.7637 C- \\
& 0.7475 A B+0.9050 A C-0.2225 B C+ \\
& 1.162 A 2-3.385 B 2-3.463 C 2
\end{aligned}
$$

As shown in quadratic equation individual factor $\mathrm{A}, \mathrm{B}$, $\mathrm{C}$ and combined factors $\mathrm{A}, \mathrm{C}$ have synergistic effect, whereas combined factors $\mathrm{A}, \mathrm{B}$ and $\mathrm{B}, \mathrm{C}$ showed antagonistic effect on entrapment efficiency. Theincrease in entrapment efficiency with increasing the values of factor A, B and C i.e. increasing \%age of bifonazole, Tristearin and Stearylamine may be due to the facts that bifonazole has direct influence in entrapment efficiency i.e. with increase in \%age of bifonazole, more amount of drug is available in solution for entrapment. Tristearin is core material and drug is entrapped in core with tristearin, more \%age of tristearin results in more amount of drug entrapped. Stearylamine is charge inducer which induces more charge density over the vesicles and in turn leads to intra-bilayer repulsion of phospholipid bilayer resulting in availability of more space between bilayer for drug entrapment. 3-D response surface plots of entrapment efficiency are shown in (Figure 4).

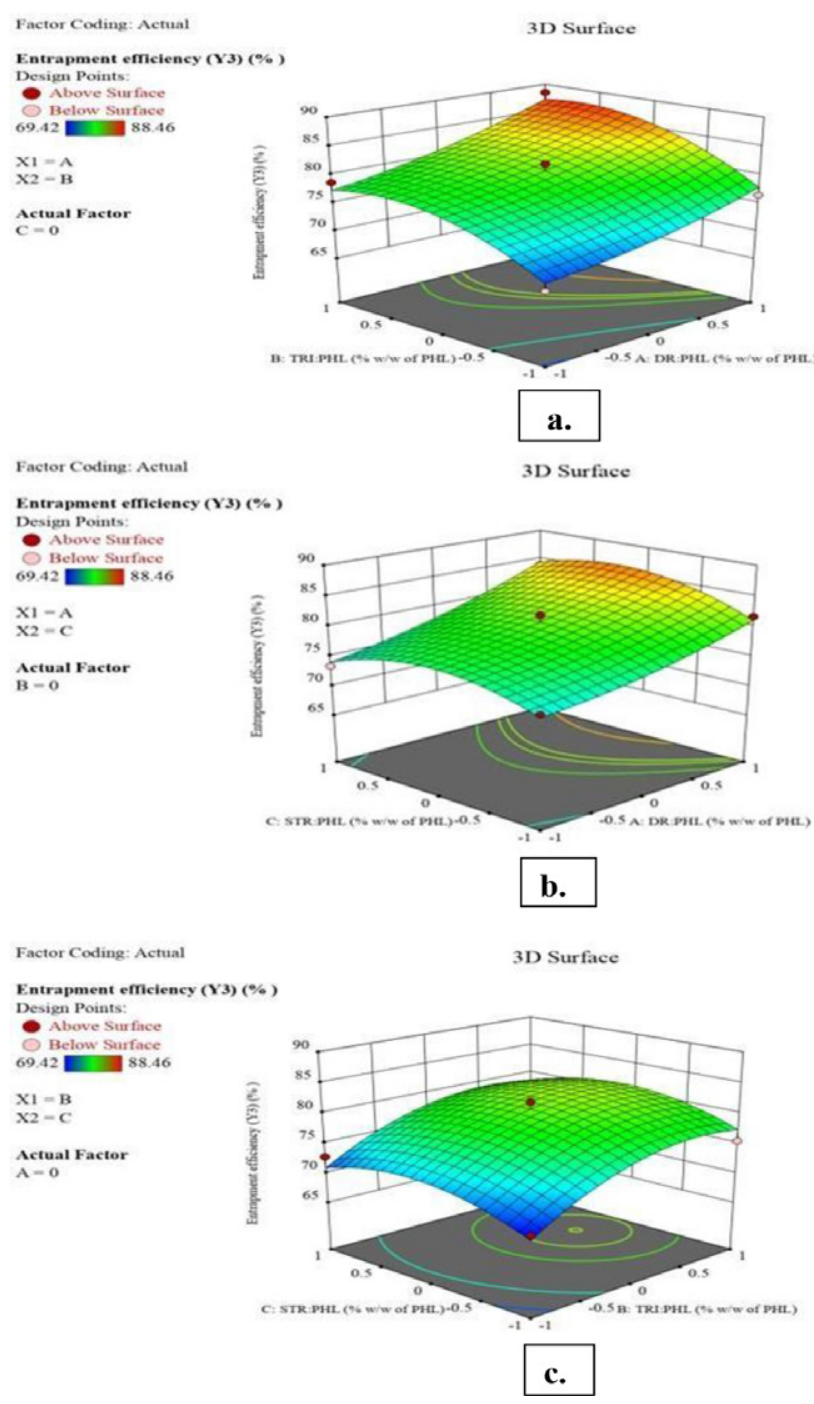

Figure 4: 3-Dimensional response surface plots showing interaction effect of variable $A$ and $B(3 a), A$ and $C(3 b)$, $B$ and $C(3 c)$ on entrapment efficiency (Y3). 
Table 7: Final Optimized combinations of variables.

\begin{tabular}{|c|c|c|c|c|c|c|c|c|}
\hline Number & DR:PHL & TRI:PHL & STR:PHL & Size (Y1) & $\begin{array}{c}\text { Zeta } \\
\text { potential (Y2) }\end{array}$ & $\begin{array}{c}\text { Entrapment } \\
\text { efficiency (Y3) }\end{array}$ & Desirability & \\
\hline 1 & 3.834 & 90.171 & 9.689 & 390.394 & 45.000 & 81.642 & 0.797 & Selected \\
\hline 2 & 3.843 & 89.792 & 9.680 & 389.752 & 45.000 & 81.617 & 0.797 & \\
\hline 3 & 3.814 & 90.281 & 9.701 & 389.510 & 45.000 & 81.607 & 0.797 & \\
\hline 4 & 3.858 & 89.570 & 9.668 & 390.002 & 45.000 & 81.626 & 0.797 & \\
\hline 5 & 3.836 & 90.925 & 9.698 & 392.735 & 45.000 & 81.733 & 0.797 & \\
\hline 6 & 3.802 & 90.866 & 9.715 & 390.579 & 45.001 & 81.648 & 0.797 & \\
\hline 7 & 3.859 & 88.883 & 9.659 & 387.920 & 45.000 & 81.544 & 0.796 & \\
\hline
\end{tabular}

Optimization of data and validation of response surface methodology

The results of experimental runs were put in the design expert software and analysed by way of quadratic equation, ANOVA, 2-dimensional and 3-dimensional response surface curves. Final optimized batch of formulation was selected on the criteria of maximum zeta potential and entrapment efficiency with minimum particle size. Design expert software had evaluated all the possible combination of variables within the design space to meet the desirability criteria. Total 7 number combinations were found out having maximum value of desirability as shown in (Table 7). Desirability value is calculated in range 0 to 1 . The value closest to 1 should be considered. In present evaluation total 7 combination of variable were selected having desirability value 0.797 . Out of these 7 combinations, 1 combination of variables is finalized based on criteria of minimum particle size and maximum zeta potential and entrapment efficiency. The selected combination as shown in Table 7 is having \% of drug 3.834, tristearin 90.171 and stearylamine 9.689 w.r.t total amount of phospholipid used.

\section{CONCLUSION}

Bifonazole loaded emulsomes were successfully formulated by modified lipid film hydration method. A 3-factor, 3-level Box Behnken design of experiment was used to optimize the formulation to find out best values of factors having maximum zeta potential and entrapment efficiency with minimum particle size. Design expert software was used to evaluate the interaction and quadratic effects of selected three factors having direct influence on particle size, zeta potential and entrapment efficiency. The factors selected were drug to phosphopilid ratio, tristearin to phospholipid ratio and stearylamine to phospholipid ratio. As evaluated by software 17 experimental batches were formulated and their responses were analysed and final optimized values of factors were find out based on desirability value of 0.797 . Optimized formulation having $\%$ of drug 3.834, tristearin 90.171 and stearylamine 9.689 w.r.t phospholipid content have predicted particle size (390.394), zeta potential (45.000) and entrapment efficiency (81.642). In conclusion, BBD can be used to optimize emulsomes formulations for studying 3-factors at 3-level with help of design expert software

\section{ACKNOWLEDGEMENT}

The authors are thankful to the Vital Labs, Gujarat for providing us with the gift sample of Bifonazole. The authors are also thankful to the principal and management of P.R. Pote Patil College of Pharmacy for providing us with the facility for carrying out the research work.

\section{CONFLICT OF INTEREST}

The author declares none.

\section{ABBREVIATIONS}

BBD: Box-Behnken design; TRI: Tristearin; STR: Stearylamine; CHOL: Cholesterol; 2-D: 2- dimensional; 3-D: 3-dimensional; UV: Ultra-violet Spectroscopy; FTIR: Fourier Transmission Infra-Red Spectroscopy; nm: Nanometre; PBS: Phosphate Buffer Saline; TRI: PHL: Phospholipid to Tristearin ratio; STR: PHL Phospholipid to Stearylamine ratio; EE: Entrapment efficiency; ANOVA: Analysis of Variance.

\section{REFERENCES}

1. Kim S. Liposomes as carriers of cancer chemotherapy. Drugs. 1993;46(4):61838.

2. Humberstone AJ, Charman WN. Lipid-based vehicles for the oral delivery of poorly water soluble drugs. Advanced Drug Delivery Reviews. 1997;25(1):103-28.

3. Yadav S, Gupta S. Development and in vitro characterization of docetaxelloaded ligand appended solid fat nanoemulsions for potential use in breast cancer therapy. Artificial Cells, Nanomedicine and Biotechnology. 2015;43(2):93-102.

4. Amselem S, Yogev A, Zawoznik E, Friedman D. Emulsomes, a novel drug delivery technology. In Proceedings of the International Symposium on Controlled Release of Bioactive Materials. 1994;21:1368-9. 
5. Vyas SP, Subhedar R, Jain S. Development and characterization of emulsomes for sustained and targeted delivery of an antiviral agent to liver. Journal of Pharmacy and Pharmacology. 2006;58(3):321-6.

6. Nair AS, Vidhya KM, Saranya TR, Sreelakshmy KR, Nair SC. Emulsomes: A novel liposomal formulation for sustained drug delivery. International Research Journal of Pharmaceutical and Applied Sciences. 2013;3(5):192-6.

7. Gill B, Singh J, Sharma V, Kumar SH. Emulsomes: An emerging vesicular drug delivery system. Asian Journal of Pharmaceutics (AJP): Free Full Tarticles from Asian J Pharm. 2014;6(2).

8. Singh B, Kumar R, Ahuja N. Optimizing drug delivery systems using systematic" design of experiments." Part I: fundamental aspects. Critical Reviews $^{\mathrm{TM}}$ in Therapeutic Drug Carrier Systems. 2005;22(1).

9. Singh B, Dahiya M, Saharan V, Ahuja N. Optimizing drug delivery systems using systematic" design of experiments." Part II: retrospect and prospects. Critical Reviews ${ }^{\mathrm{TM}}$ in Therapeutic Drug Carrier Systems. 2005;22(3).

10. Gill B, Singh J, Sharma V, Kumar SH. Emulsomes: An emerging vesicular drug delivery system. Asian Journal of Pharmaceutics (AJP): Free full text articles from Asian J Pharm. 2014;6(2).

11. Singh B, Bhatowa R, Tripathi CB, Kapil R. Developing micro-/nanoparticulate drug delivery systems using "design of experiments". International Journal of Pharmaceutical Investigation. 2011;1(2):75.

12. Gupta S, Kesarla R, Chotai N, Misra A, Omri A. Systematic approach for the formulation and optimization of solid lipid nanoparticles of efavirenz by high pressure homogenization using design of experiments for brain targeting and enhanced bioavailability. Biomed Research International. 2017.

13. Chen Z, Liu Z, Qian F. Crystallization of bifonazole and acetaminophen within the matrix of semicrystalline, PEO-PPO-PEO triblock copolymers. Molecular Pharmaceutics. 2015;12(2):590-9.

14. Liangqing FU, Dezheng WU, Luo C, Shu R. Pharmacokinetic study of bifonazole in human. Chinese Pharmaceutical Journal. 2001;1(1):43-5.
15. Malviya VR, Pande SD, Bobade NN. Preparation and Evaluation of Sustained Release Beads of Zolmitriptan Hydrochloride. Research Journal of Pharmacy and Technology. 2019;12(12):5972-6.

16. Wehrlé P, Stamm A. Statistical tools for process control and quality improvement in the pharmaceutical industry. Drug Development and Industrial Pharmacy. 1994;20(2):141-64.

17. El-Malah Y, Nazzal S, Khanfar NM. D-optimal mixture design: optimization of ternary matrix blends for controlled zero-order drug release from oral dosage forms. Drug Development and Industrial Pharmacy. 2006;32(10):1207-18.

18. Gupta S, Dube A, Vyas SP. Antileishmanial efficacy of amphotericin B bearing emulsomes against experimental visceral leishmaniasis. Journal of Drug Targeting. 2007;15(6):437-44.

19. Pal A, Gupta S, Jaiswal A, Dube A, Vyas SP. Development and evaluation of tripalmitin emulsomes for the treatment of experimental visceral leishmaniasis. Journal of Liposome Research. 2012;22(1):62-71.

20. Wang F, Chen L, Jiang S, He J, Zhang X, Peng J, et al. Optimization of methazolamide-loaded solid lipid nanoparticles for ophthalmic delivery using Box-Behnken design. Journal of Liposome Research. 2014;24(3):171-81.

21. Rathee S, Kamboj A. Optimization and development of antidiabetic phytosomes by the Box-Behnken design. Journal of Liposome Research. 2018;28(2):161-72.

22. Kraisit P, Sarisuta N. Development of triamcinolone acetonide-loaded nanostructured lipid carriers (NLCs) for buccal drug delivery using the BoxBehnken design. Molecules. 2018;23(4):982.

23. Moghddam SM, Ahad A, Aqil M, Imam SS, Sultana Y. Optimization of nanostructured lipid carriers for topical delivery of nimesulide using BoxBehnken design approach. Artificial Cells, Nanomedicine and Biotechnology. 2017;45(3):617-24.

24. Yasir M, Sara UV. Solid lipid nanoparticles for nose to brain delivery of haloperidol: In vitro drug release and pharmacokinetics evaluation. Acta Pharmaceutica Sinica B. 2014;4(6):454-63.

\section{PICTORIAL ABSTRACT}

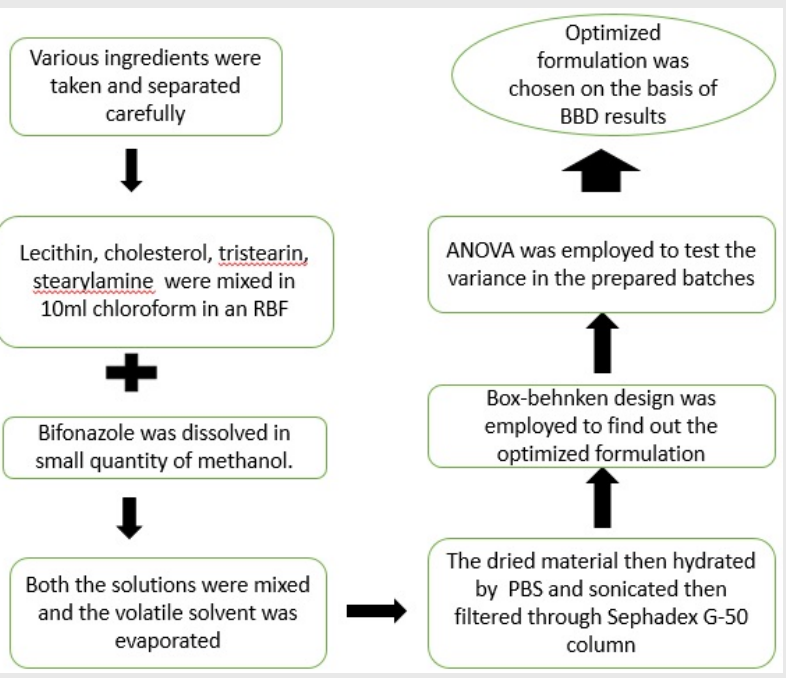

\section{SUMMARY}

Emulsomes are the modified form of liposome which consists of solid lipid core surrounded by phospholipid bilayer. The present study was performed in order to check the optimization of emulsomes formulation by applying Box-Behnken design of experiment. The antifungal drug bifonazole was chosen as the drug candidate and emulsomes were prepared by lipid film hydration method using Phosphatidylcholine, Tristearin, Stearylamine, and Cholesterol. Fromthe test the optimized formulation was chosen from the various formulation combinations from which the first combination was selected having better results than compared with other batches having the particle size of $390.394 \mathrm{~nm}$, zeta potential of $45.0 \mathrm{mV}$ and entrapment efficiency was found to be $81.642 \%$.

\section{About Authors}

Prof. Vedanshu Malviya (M.Pharm), is currently working as a assistant professor at P.R. Pote Patil College of Pharmacy, in the Department of Pharmaceutics and also published 5 Research articles in National and International Journals.

Cite this article: Malviya V. Preparation and Evaluation of Emulsomes as a Drug Delivery System for Bifonazole. Indian J of Pharmaceutical Education and Research. 2021;55(1):86-94. 